\title{
CONTRIBUIÇÃO DA ENFERMAGEM EM «CAMPUS» AVANÇADO
}

\author{
Nylza da Rocha Dias de Medeiros (*)
}

\section{1 - INTRODUÇÃO}

Com a tendência cada vez maior de tornar o ensino universitário sensível aos problemas da comunidade, preparando o estudante para desenvolver sua atividade profissional dentro da realidade brasileira, contribuindo para a solução dos problemas básicos do país, cada vez mais a Universidade expande sua ação.

A Faculdade de Enfermagem não poderia deixar de ocorrer a esse chamado de tão elevado significado social, vanguardeiro no processo da nova mentalidade de formação profissional.

\section{2 - HISTÓRICO}

Por iniciativa do Professor Choeri, atual Sub-Reitor para Assuntos de Planejamento e Coordenação Executiva da Universidade do Estado da Guanabara, foi planejada e realizada uma visita ao Território de Rondônia em 1967, com o objetivo de sensibilizar os jovens universitários para os problemas existentes no interior brasileiro. Essa atividade posteriormente foi chamada Projeto Rondon Zero e dela participaram 30 estudantes.

O nome do projeto teve em vista homenagear Cândido Mariano da Silva Rondon (1865-1958) que dedicou toda sua vida ao sertão brasileiro, contribuindo para o enriquecimento de conhecimentos geográficos, mapeando regiões até então ignoradas e estendendo linhas telegráficas. Foi o criador do Parque Nacional do Xingu e por seu profundo sentimento humanista teve seu nome indicado para o Prêmio Nobel da Paz. Com a célebre frase "Mor-

(*) Professora de Enfermagem em Saúde Pública da Universidade do Estado da Guanabara. 
rer se preciso for, matar nunca", defendeu ardorosamente os índios, dizendo que sua ferocidade era conseqüência das violências que haviam sofrido por parte dos civilizados e para protegê-los criou o Serviço de Proteção aos Indios.

Após o sucesso do Projeto Rondon Zero, formou-se, com grande entusiasmo, um Grupo de Trabalho ligado ao Ministério do Interior, constituído basicamente por universitários, tendo como objetivo planejar e executar operações que proporcionassem aos universitários dos grandes centros, um estágio no interior do país, durante as férias de fim de ano, de caráter nacional. O lema adotado foi "Integrar para não Entregar".

Novas operações se sucederam, o número de candidatos foi aumentando de tal forma, que o Grupo de Trabalho resolveu organizar uma operação de caráter regional, durante as férias do meio de ano.

Porém, a atuação em certas áreas ressentiu-se de continuidade e em decorrência dessa necessidade, teve início a instalação de Campi Avançados, sob a responsabilidade de Universidades que desenvolvessem atividades durante todo o ano.

A Universidade do Estado da Guanabara assumiu a responsabilidade do Campus Avançado de Parintins, que representa uma extrapolação da própria Universidade em localidade interiorana de infra-estrutura carente, mas que tem elevada projeção regional.

Os objetivos gerais são:

- complementar a formação profissional dos universitários, através de sua participação no desenvolvimento do País e do conhecimento das condições de trabalho no interior, integrando-os na realidade brasileira;

- desenvolver nos universitários a formação de uma mentalidade nacional, procurando fortalecer a consciência da responsabilidade social que assumiram ao entrar na Universidade;

- tornar a cidade escolhida, pólo de atração de recursos técnicos, financeiros e humanos.

O princípio básico é o voluntariado e a atuação é a do aprendizado indireto, através de prestação de serviços que se fazem de forma contínua e sistemática, permitindo modificações de caráter estrutural e para isso são firmados convênios entre a Coordenação-Geral e Órgãos Governamentais e Privados.

O Campus Avançado atua, induzindo as Escolas Universitárias a uma adequação frente às necessidades e potencialidades do interior do País. 
Os professores passam a ter novas perspectivas de ensino, reformulando seus planos de cursos, planejando trabalhos a serem executados junto com os estudantes e com eles debatendo os problemas que surgem, aplicando novos métodos de ensino na prestação planejada e orientada de serviços.

O pessoal administrativo também participa, criando e sustentando a infra-estrutura do Campus.

Os órgãos públicos e privados do interior recebem incentivos ao seu trabalho, com a mão-de-obra necessária, através das equipes de universitários.

\section{3 - ÁREA DE ATUAÇÃO}

O município sob nossa responsabilidade é Parintins, no Estado do Amazonas, que apresenta os seguintes aspectos:

\section{$3.1-$ Físicos}

Localiza-se à margem direita do Rio Amazonas, em terras fronteiriças às do Estado do Pará, com $3.646 \mathrm{~km}^{2}$.

A flora é rica e abundante, possuindo espécies de valor comercial como pau-rosa, seringueira, castanheira-do-pará, cumaru, diversos pós e ervas medicinais, além de valiosas madeiras-de-lei.

Há indicação de existência de cobalto, bauxita, cassiterita e urânio ainda não explorados e presume-se a existência de ouro, manganês, rutilo, titânio, cristal de rocha, calcários e xistos betuminosos.

Na fauna ictiológica o mais importante é o pirarucu, sendo dignos de menção os quelônios e animais silvestres como caititu, veado e queixada.

O clima é quente e úmido, chovendo abundantemente de dezembro a junho e a temperatura média é de $36^{\circ}$.

\section{2 - Demográficos}

De acordo com o Censo de 1970, a população é de 32.104, apresentando as seguintes características:

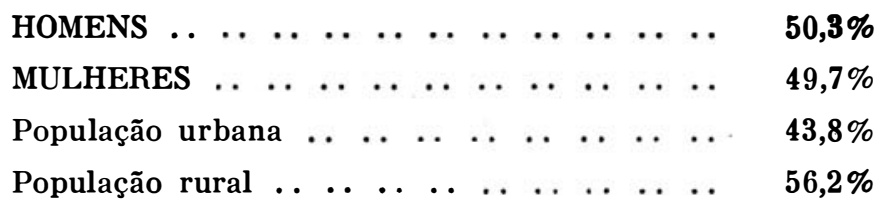


A densidade demográfica é de $11 \mathrm{hab} / \mathrm{km}^{2}$ - com um incremento de $40,6 \%$ entre os anos 1960/70.

\section{3 - Econômicos}

Os principais produtos agrícolas são: mandioca, juta, laranja, manga, abacate e tangerina.

As espécies pecuárias mais encontradas: bovinos, eqüinos, suínos, ovinos, caprinos e búfalos.

Existem criações de patos, marrecos, gansos, galinhas e perus e está sendo estimulada a produção do mel de abelha.

A pesca é realizada em 1.313 embarcações: canoas, cascos e 3 barcos a motor.

As principais produções extrativas vegetais são de: borracha, juta, pau-rosa, copaíba, castanha-do-pará, cacau, guaraná e cumaru.

A caça, para produção de peles e couros, visa principalmente: capivara, pintado, maracajá, queixada, caititu, peludo, veado, jacaré e camaleão.

A indústria existente é de transformação: minerais não-metálicos, têxtil e produtos alimentares.

Existem duas cooperativas agrícolas e uma pecuária, dois agrônomos e um veterinário.

O comércio possui três estabelecimentos atacadistas e 169 de varejo, além de 8 mistos, predominando os ramos de gêneros alimentícios, tecidos e ferragens.

O município exporta castanha-do-pará e amêndoas de cacau para o exterior e outros Estados e importa produtos farmacêuticos, material de construção, tecidos, produtos alimentícios e forragens.

Existem três agências bancárias: Banco do Brasil, da Amazônia e do Estado do Amazonas. 22 estabelecimentos prestam serviços, figurando entre eles dois hotéis, uma pensão, um restaurante, 16 bares, botequins e similares.

Os transportes se fazem por:

Via fluvial, em pequenas embarcações movidas a vapor, em viagens semanais. Empresas nacionais escalam no porto em viagens para o País e o exterior;

Via aérea, mantido pelos Serviços Aéreos Cruzeiro do Sul.

Dispõe de uma agência postal-telegráfica da ECT e o serviço de telefones intermunicipais, sistema de microondas, é explorado pela Companhia Amazonense de Telecomunicações (CAMTEL). 


\section{$3.4-$ Sociais}

Parintins situa-se na Ilha de Tupinambarana, cortado por igarapés, possuindo lagos, campos naturais e lindas praias.

Possui 38 ruas, travessas e avenidas, 1 jardim e 3 praças, sendo 12 logradouros pavimentados, 4 arborizados e 45 com iluminação pública.

Existem 2.054 prédios cadastrados, dos quais 836 possuem ligações elétricas e 1.194 são servidos pela rede de abastecimento de água.

Nas principais edificações existentes, funcionam a Prefeitura Municipal, o Foro, o Quartel e a Delegacia de Polícia, a Agência da Companhia Amazonense de Telecomunicações, os Bancos e as Escolas.

A assistência à saúde é prestada pela Unidade da Fundação SESP, a Clínica e Pronto-Socorro Santo Agostinho e dois Postos de Saúde.

Atuam no município uma enfermeira, cinco médicos e cinco dentistas e existem três farmácias.

A parte religiosa é atendida pelas Igrejas Católicas, Batistas, Adventistas do $7 .^{\circ}$ Dia, Assembléias de Deus e Cristãs Evangélicas.

\section{$3.5-$ Culturais}

$52 \%$ das pessoas acima de cinco anos são alfabetizadas. Das crianças em idade escolar, $\mathbf{7 5 , 4 \%}$ freqüentam escolas, numa percentagem bem superior à média do país que é de $66,1 \%$.

Existem 83 unidades de ensino primário, com 185 professores e 6.178 alunos.

0 ensino médio é ministrado em 2 Ginásios e 1 Escola Normal, possuindo 48 professores e 846 alunos. livros.

As 3 Bibliotecas da cidade possuem um acervo de 2.000

As diversões são proporcionadas por 2 cinemas, 1 estádio, 1 parque infantil e festas populares, das quais devemos destacar a de Nossa Senhora do Carmo em julho, a do Sagrado Coração de Jesus em outubro e a de São Benedito em dezembro, além das festas juninas e de Natal.

Circulam na cidade dois periódicos, um semanalmente com 300 exemplares e outro quinzenalmente com 200 . 

médias

A Rádio Alvorada, prefixo ZYA-56, transmite em ondas

Existem ainda 2 livrarias e uma tipografia, além de 9 associações culturais recreativas e desportivas.

\section{6 - Administrativos e Políticos}

Funcionam, entre outras, as seguintes repartições:

Posto Agropecuário, Posto da Receita Federal, Coletoria Estadual, Escritório do Sistema Brasileiro de Extensão Rural (ABCAR), dos Grupos de Defesa Sanitária Animal e Defesa Sanitária Vegetal, do Posto de Revenda da Secretaria de Produção do Estado e Agência do Instituto Brasileiro de Estatística.

0 orçamento municipal prevê receita igual à despesa.

A representação política é feita pelo Legislativo Municipal que se compõe de 6 vereadores e o número de eleitores é de 8.362.

\section{4 - ORGANIZAÇÃO DO CAMPUS}

Cada unidade da U.E.G. indica um professor como seu representante junto a um Grupo de Trabalho Universitário, que, sob a liderança de um Coordenador-Geral, tem como funções planificar, coordenar e supervisionar as atividades do Campus.

Em sua unidade, o professor representante tem como funções planejar o programa específico a ser executado, divulgar a importância do Campus junto aos demais professores, manter contato direto com o Diretor da Unidade, selecionar e orientar o treinamento da equipe, contando para isso com a colaboração de um monitor (estudante que já tenha participado de atividades no Campus).

Em Parintins, o Campus é administrado por um diretor com a colaboração de um adjunto (ambos professores da U.E.G.), responsáveis pelo desenvolvimento das atividades planejadas, para isso contando com um administrador e número suficiente de servidores locais, visando proporcionar aos estudantes moradia, alimentação e outras condições adequadas, além da coordenação em nível local.

\section{5 - ATUAÇÃO DOS ESTUDANTES}

Selecionados, os estudantes são submetidos a treinamento de 3 tipos:

5.1 - Específico, sobre as atividades que são próprias à sua especialidade. 
5.2 - Setorial, de acordo com a sua àrea de atuação:

5.2.1 - Saúde - enfermagem, medicina e odontologia, cujo objetivo é elevar o nível de saúde da comunidade;

5.2.2 - Educacional - educação, com objetivo de atingir os professores e pais, conscientizando-os da importância da Escola na Sociedade e da necessidade de constante relacionamento entre pais e mestres;

5.2.3 - Sócio-Econômico - serviço social, sociologia, direito, com o objetivo de mobilizar a comunidade em torno de seus problemas, centralizando todos os recursos para um trabalho cooperativo;

5.2.4 - Agropecuário - agronomia e veterinária, procurando fomentar a elevação quantitativa e qualitativa dos produtos agrícolas e pecuários. Os estudantes desse setor são recrutados da Universidade Rural do Rio de Janeiro, por não existir na U.E.G. as respectivas especialidades;

5.2.5 - Técnico - engenharia, geologia, descnvolvendo atividades como projetos e levantamentos topográficos, de construções, de abastecimento de água.

5.3 - Geral, com orientação sobre: o programa global a ser executado, delimitação de funções dos diversos setores, conduta a adotar, características da cidade, transporte, relatórios a serem apresentados e outras que se fizerem necessárias.

Em todas as fases de treinamento, estimula-se o estudante a participar do planejamento de sua atuação, procurando adequar o seu trabalho às necessidades e objetivos da política de desenvolvimento do Estado e do município onde irá atuar, procurando combater a mentalidade paternalista e incentivando a auto-ajuda.

A equipe, por via aérea, chega a Manaus, onde fica hospedada no Hotel de Remanejo do Projeto Rondon e no dia seguinte, também por via aérea, dirige-se a Parintins, onde no aeroporto já está sendo esperada pela aquipe anterior, que permaneceu um mês no Campus e volta no mesmo avião.

\section{6 - ENFERMAGEM NO CAMPUS AVANÇADO}

Após levantamento e análise da situação de saúde local, verificou-se que as principais causas de mortalidade infantil são doen- 
ças gastrenterotróficas e transmissíveis e as de maior morbidade, as transmissíveis, principalmente tuberculose, verminose, lepra, sarampo, doenças venéreas, malária, parotidite e tracoma.

Analisaremos, a seguir, os principais problemas e o que tem sido feito para minimizá-los:

\section{PROBLEMAS}

- Agua de má qualidade e em quantidade insuficiente (cacimbas) nas áreas não servidas pela rede de abastecimento;

-. lixo colocado em terrenos baldios e quintais;

_- fossas mal utilizadas e insuficientes;

- vetores responsáveis por doenças;

- alimentação má; - elevada incidência de tuber
culose;

- elevada incidência do sarampo;

- elevada incidência de doenças venéreas, parotidite, lepra, malária e tracoma;

\section{SOLUÇס̃ES APRESENTADAS}

- Orientação sobre o uso dos chafarizes. Tratamento da água;

- expansão da coleta pela Prefeitura. Orientação sobre o destino adequado do lixo;

- ensino de construção de fossas secas;

- orientação sobre a importância do controle dos vetores e as medidas necessárias;

- orientação sobre a qualidade e quantidade da alimentação, incentivando o uso de verduras e frutas;

- cadastro tuberculínico. Vacinação BCG. Quimioprofilaxia. Controle e tratamento adequados dos doentes. Educação sanitária;

- vacinação do grupo suscetível. Prevenção de complicações;

- Tratamento adequado dos doentes. Quimioprofilaxia, no que couber. Orientação sexual. Educação sanitária. Controle aos vetores, no que couber; 
- elevado índice de separação; de casais e de mães não casadas;

- elevado índice de nati-mortos;

- incidência de infecção puerperal, partos sem assistência adequada e tétano umbilical;

- mortalidade infantil elevada;

- elevada incidência de verminose e desnutrição em pré-escolares e escolares;

-- prostituição das adolescentes.
- orientação sobre o casamento, despertando os jovens para a importância da família e responsabilidade conjugal;

- melhor assistência às gestantes;

- cadastramento e orientação de curiosas. Vacinação antitetânica das gestantes;

- orientação sanitária à s gestantes, mães e jovens;

- orientação alimentar. Tratamento e profilaxia das verminoses;

— orientação sexual.

Assim, a Enfermagem vem contribuindo para o Campus, desenvolvendo as funções que lhe são próprias:

Técnicas, prestando cuidados integrais a indivíduos, famílias e grupos da comunidade.

As atividades desenvolvidas em maior escala são as preventivas, vindo a seguir os curativos e reabilitativas, através de consultas de enfermagem, orientação pós-clínica, vacinações, testes tuberculíneos, visitas domiciliares e outras. fermagem.

Está sendo incentivado o início de pesquisas locais de en-

Educativas, foram realizadas várias atividades de Orientação Sanitária, utilizando métodos modernos de ensino e com a utilização de material audio-visual.

Cursos de Puericultura, Socorros Urgentes e a Curiosas, programas radiofônicos, utilizando dramatizações sobre assuntos prioritários de saúde.

Também foi realizado treinamento de pessoal auxiliar local.

Administrativas, todas as fases do processo administrativo de enfermagem são desenvolvidas pelos estudantes, do planejamento à 'avaliação.

\section{7 - CONSIDERAÇס̃ES GERAIS}

Os principais aspectos positivos da experiência para o estudante são:

7.01 - Sente-se realizado por contribuir efetivamente no esforço de desenvolvimento no País. 
7.02 - Adquire experiência na sua profissão de forma realística.

7.03 - Estimula a criatividade e a iniciativa.

7.04 - Desenvolve o espírito de liderança e de equipe.

As principais dificuldades:

7.05 - Diferença cultural existente entre os estudantes e a população local.

7.06 - Adequação dos planejamentos às necessidades reais sentidas pela população local.

7.07 - Descontinuidade de coordenação central que determina muitas vezes um treinamento inadequado às equipes, antes do embarque.

7.08 - Alguns estudantes, por motivação inadequada, acham que está em suas mãos mudar rapidamente a situação local e não conseguindo, sentem-se frustrados.

7.09 - 0 etnocentrismo dos estudantes, que necessitam melhor formação no que se refere a trabalho em equipe multiprofissional.

7.10 -- Contato superficial entre a equipe que chega e a que sai em Parintins.

Muitos aspectos na experiência que está sendo realizada necessitam ser reformulados, mas estabelecendo uma comparação entre pontos positivos e os negativos, os primeiros suplantam os segundos, o que torna válido o esforço dispendido, dado o papel de relevância econômica que representa a elevação do nível educacional e de saúde de nosso País.

\section{8 - CONCLUSÕES}

8.1 - O Campus Avançado induz a Universidade a uma adequação frente às necessidades e potencialidades do interior do País.

8.2 - Aos professores que para lá são enviados, abrem-se novas perspectivas de ensino, elaborando planejamentos de trabalho e debatendo-os com os estudantes.

8.3 - Os estudantes adquirem novos meios de aprendizado, através da prestação planejada e orientada de serviços.

8.4 - Os órgãos públicos e privados do interior recebem mão-de-obra necessária aos seus trabalhos através das equipes de universitários, mantidos em regime permanente. 
8.5 - Há necessidade de analisar os dados coletados, verificando se o programa desenvolvido corresponde às necessidades locais, e, em caso contrário, reformulá-los.

\section{9 - REFERENCIAS BIBLIOGRÁFICAS}

Dados obtidos no IBE - Fundação IBGE - Ministério do Planejamento e Coordenação Geral.

Estatísticas da FSESP.

Planejamentos e relatórios apresentados por professores e estudantes da Faculdade de Enfermagem da UEG. 